\title{
Virchow's Contribution to the Understanding of Thrombosis and Cellular Biology
}

David R. Kumar, BS; Erin R. Hanlin, BS; Ingrid Glurich, PhD;

\author{
Keywords: \\ Virchow \\ Virchow's Triad \\ DVT \\ History \\ Corresponding Author: \\ Steven H. Yale, MD \\ Department of Clinical Research \\ Marshfield Clinic Research Foundation \\ 1000 North Oak Avenue \\ Marshfield, WI 54449 \\ Tel.: 7|5-387-9|10 \\ Fax: 715-389-5757 \\ E-mail: yale.steven@marshfieldclinic.org \\ Received: June 22, 2009 \\ Revised: September 3, 2009 \\ Accepted: September 9, 2009 \\ doi: $10.3121 / \mathrm{cmr} .2009 .866$
} Joseph J. Mazza, MD; and Steven H. Yale, MD

\author{
Joseph J. Mazza, MD; and Steven H. Yale, MD
}

$\mathrm{F}$ understanding of the pathophysiology of cellular biology as Rudolf Virchow. His contribution to the cellular biomedicine paradigm along with the germ theory of Pasteur and Koch formed the basis for many of the medical advances of the twentieth century. ${ }^{1}$ He was one of the first physicians to examine disease at the cellular level, arguing that the origin of disease was caused by cellular pathology. One area that he studied extensively, and in which he has left lasting contributions to modern medicine, was in the area of thrombosis, specifically venothromboembolism (VTE). For much of the later half of the twentieth century, the so-called Virchow's Triad has formed the basis for understanding the pathogenesis of VTE and is still widely used to assess VTE risk. ${ }^{2}$ In order to assess and appreciate the applicability of Virchow's Triad to current medical practices, it is important first to examine how the principals of Virchow's original theory of thrombosis continue to be applicable to modern day theory.

\section{Virchow at a Glance}

Virchow was born in Pomeranian Prussia on October 13, 1821, and attended the Friederich-Wilheim Institute, a division of the University of Berlin, graduating in 1843. ${ }^{3}$ His writings as a student were as diverse as his later work and included essays such as "Rheumatic Disease, Particularly of the Cornea" and "Only the Liberal Minded Can Gain Insight into the Future of Medicine."”3 After graduation, Virchow quickly gained success as a clinician and researcher, and was appointed "company surgeon" at the military medical center Charité Hospital in 1845, at the age of $24 .{ }^{3}$ He presented a paper to an audience consisting mainly of his superiors entitled "On the Need and Correctness of Medicine Based on a Mechanistic Approach" in which he emphasized the need for research based on clinical observation, experimentation in animals, and necropsy. ${ }^{4}$ In 1856, Virchow published a collection containing ten years of previous work titled "Collective Treatises on Scientific Medicine," which contained his detailed studies of embolization following venous thrombosis. ${ }^{4}$ In 1847, he taught courses in pathological anatomy, and with Reinhardt as co-author, published the first volume of Archives for Pathological Anatomy and Physiology and Clinical Medicine. ${ }^{3}$

\section{Politics}

Virchow was active in politics and medical reform. In 1847, a typhus epidemic occurred in Upper Silesia, a Prussian province inhabited by a Polish minority. Virchow was appointed to survey the medical situation. In his report, he 


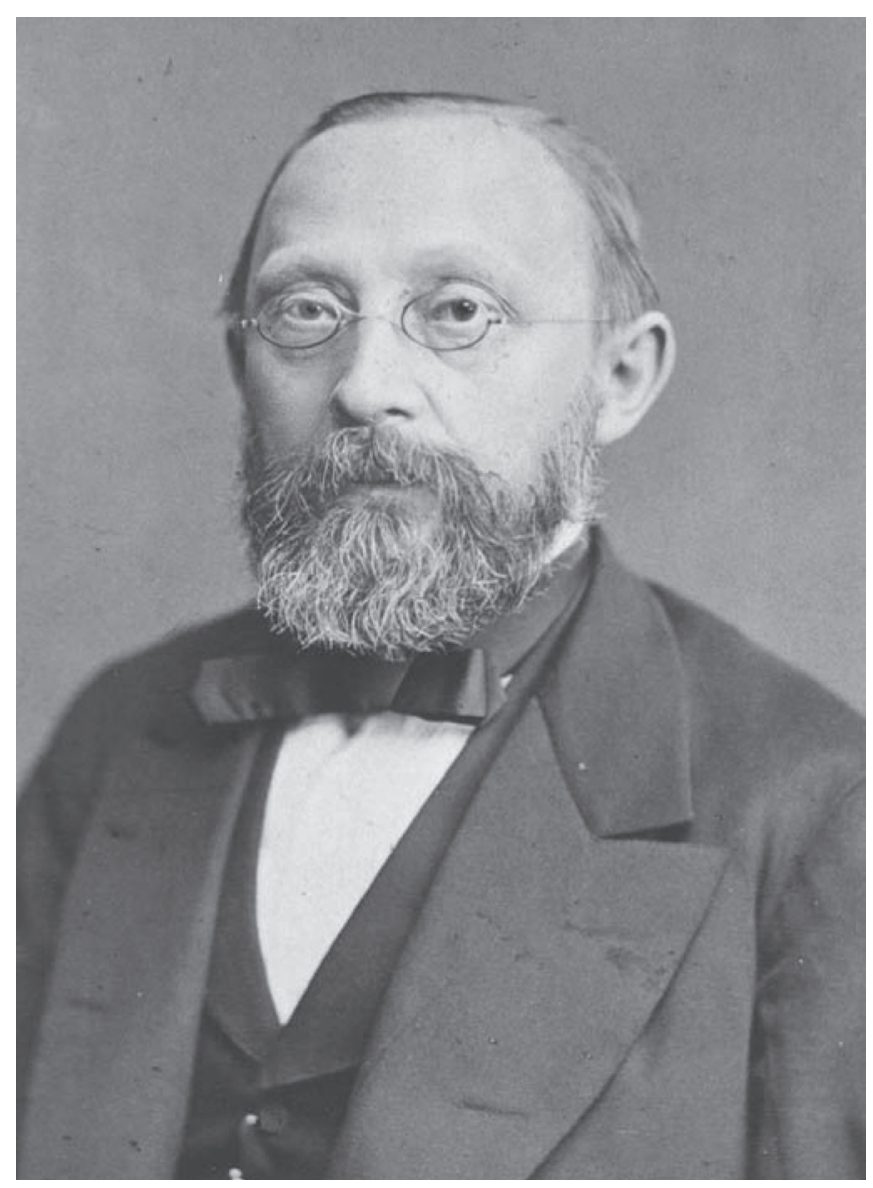

Figure 1. Rudolf Virchow (1821-1902). Courtesy of the National Library of Medicine.

admonished the government for the epidemic and stated, "the answer to the question of how to prevent outbreaks in Upper Silesia is quite simple: education, together with its daughters, freedom and welfare." 5 His experiences in Upper Silesia were to be the foundation for his political career. He argued that "the physician is the natural attorney for the poor," and that "the improvement of medicine would eventually prolong human life, but improvement of social conditions could achieve this result now more rapidly and more successfully." ${ }^{\prime, 7}$ In Prussia, the mid to late $19^{\text {th }}$ Century was dominated by Nationalistic views that de-emphasized the importance of individual liberties and interests. ${ }^{8}$ As a result, many of Virchow's proposed ideas that were aimed at the health and well-being of the individual were considered radical or extreme. In addition to being a proponent for democracy, the separation of church and state, and social welfare programs, some of Virchow's other ideas included medical care for the impoverished, prohibition of child labor, protection for pregnant women, decrease of the work day in hazardous jobs, and improved working conditions., ${ }^{79}$ Revolutionary at the time, these principles have become commonplace in $21^{\text {st }}$ century politics.

The idea of medical social justice would permeate most of his life. He participated in the revolutions in Berlin and was elected to the Berlin City Council, where his focus was on improving public health by developing systems for water and sewer disposal, advocating for school physicians, and providing input to cities and states in the planning of hospitals. ${ }^{10} \mathrm{He}$ also played a crucial role in establishing the capital's medical statistics, which monitored and recorded death rates, infant mortality, and causes of death. ${ }^{11}$ Consequently, this improved the standard of care as it gave physicians and health care workers a way to measure outcomes and focus on areas that needed improvement. He co-founded the German Progressive Party and was elected into the Prussian parliament and later to the Reichstag. ${ }^{3} \mathrm{He}$ stood in staunch opposition to Prussian Chancellor Otto von Bismarck, who was so incensed that the Chancellor challenged Virchow to a duel. All his work for medical reform and social justice has earned him the modern title of "the father of social medicine." 7

As a result of his political stance regarding the epidemic in Upper Silesia, Virchow was suspended from Charité in 1849. Upon his dismissal from Charité, he was able to secure a professorship at the University of Würzburg in Bavaria and became Chair of the Department of Pathological Anatomy. ${ }^{9,12}$ He was later asked to return to Berlin to teach pathological anatomy, but agreed only under the condition that a special building to house a new pathological institute be erected; consequently, the Berlin Pathological Institute was built.9,12 The institute would train many scientists who would later become leaders in their fields including Friedrich von Recklinghausen, who served as one of Virchow's assistants, and William Osler, who stayed at the institute for 3 months in $1873 .^{3,13}$

In 1858, Virchow presented a series of 20 lectures to a group of practicing physicians in Berlin at the Institute of Pathology. ${ }^{10}$ These lectures were subsequently published that same year in a book entitled Cellular Pathology as Based upon Physiological and Pathological Histology (English Translation). ${ }^{11,14}$ He was the first to postulate that the basic units of life are the selfreproducing cells of living bodies, and he summarized this cell theory with the Latin phrase omnis cellula a cellula [all cells arise from cells]. ${ }^{11,15,16}$ Although Schleiden (1838) and Schwann (1839) had previously described cells as building blocks of all plants and animals, Schwann's theory was that the intercellular substance called the cytoblastema was the origin of new cells. ${ }^{15,17}$ Virchow, on the other hand, argued that new cells arose from old cells and that the intercellular space was excreted by existing cells. , $^{3,15}$

It was also during these lectures that Virchow outlined what has become the modern paradigm for pathology. Virchow theorized that pathogenesis originated at the cellular level from single cells. This theory would later be called "cellular pathology." He outlined systematic methods for the field of pathology based on experimentation and observation, and demonstrated that cell theory applied to both diseased and healthy tissue. ${ }^{16,17}$ Virchow noted that the organism as a whole 
did not become diseased but instead only certain cells or group of cells. In his lecture "Physiological and Pathological Tissues," Virchow stated that every pathological structure has a physiological prototype. ${ }^{15}$ In attempting to explain the transition between the physiological and the pathological before the word mutation had been coined, Virchow wrote, "In the place of the law of continuity, therefore, we must place something else. And here, I think, the doctrine that has the strongest claim to our attention is histological substitution." Here Virchow was attempting to define what would later be coined "metaplasia."'15

\section{Early Work on Thrombosis}

Virchow began his research of thrombosis and pulmonary embolism by describing a blood clot as a network of fibers where blood cells have become embedded. ${ }^{14}$ Virchow created the terms thrombosis and embolism and argued that a clot in the pulmonary arteries or veins is not de novo but instead originates in the peripheral vascular system. ${ }^{4,14}$ He described the pathogenesis of pulmonary embolization as a process wherein:

New masses of coagulum deposit themselves from the blood upon the end of the thrombus layer after layer. The thrombus is prolonged beyond the mouth of the branch into the trunk in the direction of the current of the blood, shoots out in the form of a thick cylinder farther and farther, and becomes continually larger and larger. It is these prolonged plugs that constitute the source of real danger; it is in them that ensues the crumbling away, which leads to secondary occlusions in remote vessels. Thus we see that as a rule all the thrombi from the periphery of the body produce secondary obstructions and metastatic deposits [emboli] in the lungs. ${ }^{14}$

He noted that the symptoms of pulmonary embolism ranged from sudden death to silent emboli. ${ }^{18}$

In 1856, Virchow described the consequences of a pulmonary embolus that migrated from the venous circulation, which later came to be known as Virchow's Triad. ${ }^{4,19,20}$ As it is has come to be known today, the triad consists of stasis, vessel damage, and hypercoagulability, and is used to describe the etiology and assess the risk of thrombosis, especially of deep vein thrombosis (DVT. $)^{2,19}$

Standing the test of time, it is still believed that at least 2 of these 3 factors occurring concurrently increase a patient's risk of developing DVT; stasis is thought to be the most predominant of the 3 factors, and when combined with either hypercoagulability or vessel damage a clot usually forms. ${ }^{21}$ Abnormalities of rheological properties of blood cells caused by such factors as turbulence at bifurcations and large vessels burdened by an irregular lumen (eg, atheroma or stenotic regions) results in stasis. ${ }^{22}$ Clinically, stasis may be manifest by such factors as immobilization; limb paralysis due to stroke, plaster cast or spinal injury; heart failure; varicose veins; and chronic venous insufficiency ${ }^{23}$ Vascular damage is the result of any abnormality affecting the vessel wall resulting in disruption to the endothelium. ${ }^{22}$ Direct or indirect vessel injury may arise from recent surgery, central venous catheter, trauma, chemotherapy, vasculitis, sepsis, and hyperhomocysteinemia. ${ }^{23}$ Finally, abnormalities in platelets as well as in the coagulation and fibrinolytic pathways contribute to hypercoagulability. ${ }^{22}$

\section{Attribution of Virchow's Triad}

Recently, there has been much debate surrounding the origin of Virchow's Triad, which has resulted in a closer inspection of his experiments on thrombosis and emboli (1856) to determine if his findings have indeed become misinterpreted over time. , $^{420,24}$ In fact, mention of a Virchow's Triad does not occur in either books or journal articles until 1950 and even later than that in major pathology texts. ${ }^{4,20}$

In his description about 200 years prior to Virchow, Richard Wiseman, a surgeon to King Charles II, provides two factors, "depending of the Part or from some other pressure upon the Vessel" and "by its own [the blood's] grossness", to explain thrombosis. These factors have now come to be known as "stasis" and "hypercoagulability" respectively, which are two of the three tenets of Virchow's Triad. ${ }^{4}$ Gabriel Andral, who is considered the founder of hematology, observed in 1830, decades before Virchow, that stasis, inflammation of the endothelium, and an increased tendency for the blood to coagulate are all risk factors for venous thrombosis. ${ }^{20,24}$

The humoral theory of disease, presuming that all diseases start in the blood, was still an important component of medicine at the start of Virchow's career. The age of Romanticism still permeated medicine in Germany in the $19^{\text {th }}$ century, with hypotheses being put forward based on little evidence and little importance placed on observation and experimentation. ${ }^{8,9,13,25}$ Robert Froriep, a professor of Virchow who exposed him to the more progressive scientific ideas of France and England, challenged Virchow to disprove the notion that "phlebitis dominates all pathology," a claim made by French pathologist Jean Cruveilhier., ${ }^{3,46,20}$ Not only was phlebitis believed to be the precursor for all diseases, but it was also thought to be the cause of pulmonary thrombosis. ${ }^{4,20}$ Lastly, many of Virchow's contemporaries believed that thrombi in the pulmonary arteries formed de novo in the pulmonary circulation rather than initially forming in the venous circulation. ${ }^{4,19}$

Virchow approached his experiment with the goal of demonstrating that inflammation is secondary to thrombosis, and pulmonary thrombosis does not occur in situ but arises in the venous circulation. ${ }^{4}$ After performing a series of experiments in which foreign objects were introduced into the jugular vein of dogs, it was observed that the blood was able to carry these foreign bodies to the pulmonary arteries. ${ }^{4,19}$ These experiments supported the hypothesis that the 
inflammation is a secondary phenomenon to thrombosis, and pulmonary emboli result from thrombus within the venous circulation. ${ }^{4,19}$ Virchow then examined the pulmonary embolus in greater detail and stated:

In all cases the blood formed more or less extensive clots around the introduced body ... the list of possible consequences of the obstruction could be grouped into three categories;

Phenomena due to the irritation of the vessel and its surroundings;

Phenomena due to blood coagulation;

Phenomena due to the interruption of the bloodstream $^{26}$

While this can be misconstrued to be the factors involved in increasing one's risk for DVT (ie, endothelial damage, hypercoagulability, and stasis), it is clear that Virchow was trying to explain the consequences of a pulmonary embolism. ${ }^{4,20}$ However, we may be able to overlook this nuance if we realize that the three factors resulting from a thrombus are the same factors involved in the formation of a thrombus. ${ }^{4,19}$ The fact that Virchow never appeared to link the two should not detract from his findings. Similar to the way in which advances are brought forth in other disciplines, it is through the collective work of many that lead to the most ground-breaking and revolutionary discoveries. It was as a result of Virchow's emphasis on clinical observation, experimentation, pathological anatomy, and the desire to obtain evidence to support his hypotheses that allowed for the breakthrough to finally occur. ${ }^{4}$

\section{Conclusion}

Although the origin of Virchow's Triad is unclear, it has undoubtedly left a lasting effect on modern clinical practices, simplifying the complicated process of thrombosis in the clinical setting, both on its own and as a basis for more advanced assessments. Advances in molecular biology as well as knowledge of pathophysiology have provided more sophisticated tools and expanded the triad to account for the role of the endothelium, platelets, and soluble coagulation factors contributing to thrombosis. ${ }^{20}$ Additional astute clinical observations attributed to Virchow include the presence of a left supraclavicular lymph node, suggesting an intra-abdominal tumor (Virchow's Node), and his accurate description of the amorphous stained extracellular material of the cerebral corpora amylacea which he termed amyloid. This term, along with more than 50 others, have become commonplace in medical language. ${ }^{13,27}$ These facets illustrate Virchow's unique desire to attain, as written in a letter from Virchow to his father, "no less than a universal knowledge of nature from Godhead to stone."' In the latter half of Virchow's career he devoted less of his time to medical research and focused his efforts towards the field of physical anthropology. ${ }^{13}$ By that time he had already cemented his place in history as one of the pioneers and forward thinkers in medicine alongside Osler and Harvey.
Virchow died on September 5, 1902 from, coincidentally, cardiac disease after sustaining a femur fracture and being immobile. His main contributions to medicine emanated from his observational skills and abilities to accurately deduce cellular processes that contributed to both health and disease. Many of his observations remain accurate to this day and scientists are in many instances only beginning to unravel the molecular pathways underlying the observations made by this physician nearly 150 years ago.

\section{References}

1. DeWalt DA, Pincus T. The legacies of Rudolf Virchow: cellular medicine in the 20th century and social medicine in the $21^{\text {st }}$ century. Isr Med Assoc J 2003;5:395-397.

2. Malone PC, Agutter PS. The aetiology of deep venous thrombosis. Q J Med 2006;99:581-593.

3. Byers JM $3^{\text {rd }}$. Rudolf Virchow-father of cellular pathology. Am J Clin Pathol 1989;92(4 Suppl 1):S2-S8.

4. Bagot CN, Arya R. Virchow and his triad: a question of attribution. Br J Haematol 2008;143:180-190.

5. Taylor R, Rieger A. Medicine as social Science: Rudolf Virchow on the typhus epidemic in Upper Silesia. Int J Health Serv 1985; $15: 547-559$.

6. Virchow RC. Report on the typhus epidemic in Upper Silesia.1848. Am J Public Health 2006;96:2102-2105.

7. Eisenberg L. Rudolf Virchow: the physician as politician. Med War 1986;2:243-250

8. Walton KN. Rudolf Virchow (1821-1902). Invest Urol 1965;2:512-514.

9. Reese DM. Fundamentals: Rudolf Virchow and modern medicine. West J Med 1998;169:105-108.

10. Plaut A. Science and man: a message to us from Rudolf Virchow (1821-1902). Bull Menninger Clin 1953; 17:209-218.

11.Ventura HO. Profiles in cardiology. Rudolph Virchow and cellular pathology. Clin Cardiol 2000;23:550-552.

12.Thomas R. Rudolf Virchow: pathologist, public health physician, liberal politician, anthropologist, and opponent of anti-Semitism. J Med Biogr 1999;7:200-207.

13. Haas N. The man behind the eponym. Rudolf Virchow (18211902). A short overview of his work in dermatology. Am J Dermatopathol 1989;11:270-275.

14. Virchow RC. Cellular Pathology as based upon physiological and pathological history. [Tr. from the 2 nd ed. of the original by Frank Chance.] Birmingham; Gryphod Editions, Ltd; 1978.

15. Wagner RP. Anecdotal, historical, and critical commentaries on genetics. Rudolph Virchow and the genetic basis of somatic ecology. Genetics 1999;151:917-920.

16.Garrison FH. The Nineteenth Century: The Beginning of Organized Advancement of Science. In: An Introduction to the History of Medicine. $4^{\text {th }}$ Edition. Philadelphia, PA; W.B. Saunders Company; 1929. 407-670.

17. Safavi-Abbasi S, Reis C, Talley MC, Theodore N, Nakaji P, Spetzler RF, Preul MC. Rudolf Ludwig Karl Virchow: pathologist, physician, anthropologist, and politician. Implications of his work for the understanding of cerebrovascular pathology and stroke. Neurosurg Focus 2006;20:E1.

18. Owen CA. Current methods of therapy: heparin. In: Nichols WL, Bowie EJW, eds. A History of Blood Coagulation. Rochester, MN: Mayo Foundation for Medical Education and Research; 2001. 169-176.

19. Brotman DJ, Deitcher SR, Lip GYH, Matzdorff AC. Virchow's Triad Revisited. South Med J 2004;97:213-214.

20. Dickson BC. Venous thrombosis: on the history of Virchow's Triad. Univ Toronto Med J 2004;81:166-171. 
21. Mammen EF. Pathogenesis of venous thrombosis. Chest 1992;102(6 Suppl):640S-644S.

22. Chung I, Lip GYH. Virchow's triad revisited: blood constituents. Pathophysiol Haemost Thromb 2003/2004;33:449-454.

23. Merli GJ. Pathophysiology of venous thrombosis, thrombophilia, and the diagnosis of deep vein thrombosispulmonary embolism in the elderly. Clin Geriatr Med 2006;22:75-92.

24. Dickson BC. Virchow's Triad? South Med J 2004;97:915-916.

25. Rather LJ. Rudolph Virchow and scientific medicine. AMA Arch Intern Med 1957;100:1007-1014.

26. Virchow RC. Thrombosis and Emboli. [Tr. by Matzdorff AC, Bell WR.] Canton, MA: Science History Publications; 1998.

27. Sipe JD, Cohen AS. Review: history of the amyloid fibril. J Struct Biol 2000;130:88-98.

\section{Author Affiliations}

David R. Kumar, BS*; Erin Hanlin, $B S^{\dagger}$;

Ingrid Glurich, PhD $D^{\dagger}$; Joseph J. Mazza, $M D^{\S}$;

Steven H. Yale, $M D^{\S}$

*University of Wisconsin, School of Medicine and Public Health, Madison, Wisconsin, USA

tUniversity of Wisconsin-Stevens Point, Stevens Point, Wisconsin, USA

Marshfield Clinic Research Foundation, Office of Scientific Writing and Publication, Marshfield, Wisconsin, USA

$\S_{\text {Marshfield Clinic Research Foundation, Department of }}$ Clinical Research, Marshfield, Wisconsin, USA 